\title{
Global hydrogen production in subducting slabs
}

\author{
ANDREW MERDITH ${ }^{1}$, ISABELLE DANIEL ${ }^{2}$, ALBERTO \\ VITALE BROVARONE ${ }^{3}$, DIMITRI SVERJENSKY ${ }^{4}$, MURIEL \\ ANDREANI $^{5}$ AND SIMON WILLIAMS ${ }^{6}$ \\ ${ }^{1}$ Université Claude Bernard Lyon 1, Laboratoire de Géologie de \\ Lyon: Terre, Planètes et Environnement, France \\ ${ }^{2}$ Laboratoire de géologie de Lyon UMR 5276, Université Lyon1 \\ - Ens de Lyon - CNRS \\ ${ }^{3}$ Università di Bologna \\ ${ }^{4}$ Johns Hopkins University \\ ${ }^{5}$ Laboratoire de géologie de Lyon UMR 5276, ENS et Université \\ Lyon 1 \\ ${ }^{6}$ Northwest University \\ Presenting Author: a.s.merdith@leeds.ac.uk
}

Subduction processes represent a unique environment, where tectonic, geological and geochemical processes interact to produce distinctive mineral assemblages that fundamentally alter the rheology and nature of the subducted rocks. Serpentinisation in subduction zones is one such process, whereby lithospheric mantle is hydrated and as it subducts is metamorphosed to serpentinite. This process releases hydrogen as a by-product, and is thought to be important for sustaining microbial communities, and could possibly have implications for earthquake generation and arc-fluxes. However, the global production of hydrogen during high-pressure serpentinisation in subduction zones has not yet been quantified. Here we used a series of discrete data sets that collectively provide a thorough geophysical and geological description of subduction zones globally, including recently $(<10$ Ma) subducted material, slab geometry (depth, dip, strike), thermal properties (temperature and pressure), tectonic history (convergence rate, subduction volume) and peridotitic content of subducting oceanic lithosphere. By linking all of these disparate data-sets together to estimate the global volume of subducted residual abyssal peridotite (RAP, peridotite exhumed at slow spreading ridges that is not serpentinised) over the last $5 \mathrm{Ma}$, we determined the amount of hydrogen that could be generated in subduction zones consistent with the stability of antigorite. Our results suggest that $\sim 1.8 \cdot 10^{17}$ moles of $\mathrm{H}_{2}$ are liberated through the serpentinisation of RAP in subduction per million year (averaged over the last $5 \mathrm{Ma}$ ). This estimate does not include any possible serpentinisation of the mantle lithosphere during trench flexure or serpentinisation of the mantle wedge. Our analysis also suggests that the dip angle of a subduction zone exerts the strongest control on $\mathrm{H}_{2}$ production, because steeper-dipping subduction zones force more RAP into the 'antigorite window' during the subduction. 